\title{
The role of STAT3 in the colorectal cancer therapy
}

\author{
Katarzyna Papierska \\ Department of Pharmaceutical Biochemistry, \\ Poznan University of Medical Sciences \\ (iD) https://orcid.org/0000-0002-5301-7944 \\ Violetta Krajka-Kuźniak \\ Poznan University of Medical Sciences, \\ Department of Pharmaceutical Biochemistry \\ (iD) https://orcid.org/0000-0001-7275-0298 \\ Corresponding author: vkrajka@ump.edu.pl
}

DOI: https://doi.org/10.20883/medical.e427
Keywords: STAT3, colorectal cancer, kinase JAK, SOCS proteins

Published: 2020-07-28

How to cite: Papierska K, Krajka-Kuźniak V. The role of STAT3 in the colorectal cancer therapy. JMS [Internet]. 2020 Jul 28;89(3):e427. doi:10.20883/medical.e427

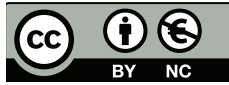

(c) 2020 by the author(s). This is an open access article distributed under the terms and conditions of the Creative Commons Attribution (CC BY-NC) licencse. Published by Poznan University of Medical Sciences

\begin{abstract}
Colorectal cancer is a type of a malignant tumor in the digestive system and its incidence rate in the United States and the European Union increases by an average of $4.2 \%$ to $4.6 \%$ annually. Colorectal cancer is a common tumor affecting rather elderly than younger individuals. An increasing number of studies prove that deregulation of the signaling pathway and abnormal expression and activation of genes can be the main reason for the development of colorectal cancer. Signal transducer and activator of transcription (STAT3) is a transcription factor of signal transduction and transcriptional activation of target genes and plays important roles in proliferation, differentiation apoptosis and other physiological processes. Several data confirm that abnormal activation of STAT3 is involved in the development of tumors. Identifying compounds that inhibit STAT3 is a promising strategy for cancer chemoprevention and treatment of colorectal cancer. In this review, the roles of STAT3 in pathogenesis and treatment of colorectal cancer are discussed.
\end{abstract}

\section{Introduction}

Colorectal cancer (CRC) is the second most common cancer diagnosed in women and the third most common in men. The prevalence of CRC increases at an average rate of $2.5 \%$ annually. Moreover, the incidence of CRC worldwide is predicted to increase to 2.5 million new cases in 2035 [1]. Epidemiological studies have shown the strong dependence of the disease incidence on gender, males, and increasing age. Additionally, diet, lifestyle, medications, smoking, obesity and a sedentary lifestyle were associated with an increased risk of CRC. Moreover, genetic changes may play a crucial role in CRC pathogenesis [2].
CRC develops through a multistage process characterised by the accumulation of aberrant protein expression, which results in the formation of tumour cells [3]. Recently, increasing attention has been focused on transcription factors contributing to oncogenic signalling pathways such as signal transducer and activator of transcription (STAT3) $[4,5]$. Persistent STAT3 activation is described in several neoplasias, including CRC. Blocking STAT3 in cultured CRC cells inhibits cell proliferation and induces apoptosis [6]. Although STAT3 is required for the survival of normal intestinal epithelial cells, long-term interference with STAT3 activation could promote gastrointestinal damage. Hence, STAT3 is a potential therapeutic target for CRC $[7,8]$. 


\section{Structure of STAT3}

STAT3 belongs to the STAT family proteins and contains six domains: N-terminal domain (ND), coiled-coil domain (CCD), DNA binding domain (DBD), the linker region, Src homology domain (SH2), and a C-terminal transcriptional activation domain (TAD) (Figure 1). The ND domain stabilises the dimerised STAT3, promoting the formation of tetramers of two STAT3 dimers for more stable binding with DNA. The CCD domain mediates STAT3 direct binding to the receptor and promotes STAT3 phosphorylation on the 705tyrosine site (Y705). The DBD domain initiates transcriptional activation of the target genes, while the $\mathrm{SH} 2$ domain plays a critical role in signal transduction. The TAD domain possesses conserved phosphorylation sites at Tyr705 and Ser727, and SH2 can recognise phosphotyrosine residues, thus are closely related to STAT3 activation $[6,9]$.

STAT3 possess four isoforms: STAT3a, STAT3 $\beta$, STAT3Y, and STAT3ס, with STAT3 $a$ being the most common and consists of ND, CCD, DBD, Linker, SH2 and TAD domains. STAT3a is associated with the proliferation and transformation of cells [9].

\section{Activation of STAT3}

The classical STAT3 signalling pathway is activated through the binding of interleukins, cytokines or growth factors to their corresponding cell surface receptors (Table 1).

In normal conditions, STAT3 is situated in the cytosol, dimerising and translocating to the nucleus after being activated via phosphorylation of the tyrosine705 residue. In the nucleus, it controls the transcription of several apoptotic and cell cycle regulatory proteins [10]. STAT3 can be activated through Janus kinase (JAK), Ras/ mitogen-activated protein kinase (MAPK) and non-receptor tyrosine kinase signalling pathways [11]. The JAK phosphorylates tyrosine residues on STAT3, especially at the Y705 site, leading to activation and dimerisation of STAT3, subsequent transport to the nucleus and binding to the GAS sequence for the initiation of the transcription of target genes [12]. Ras-MAPK phosphorylates the serine residue in STAT3 on S727, which leads to STAT3 dimerisation and its translocation to the nucleus, it also binds to DNA sequences in the promoters of genes [13]. The non-receptor tyrosine kinases such as activated Src kinase and MAPK family members (p36, ERK, JNK), PKC ,

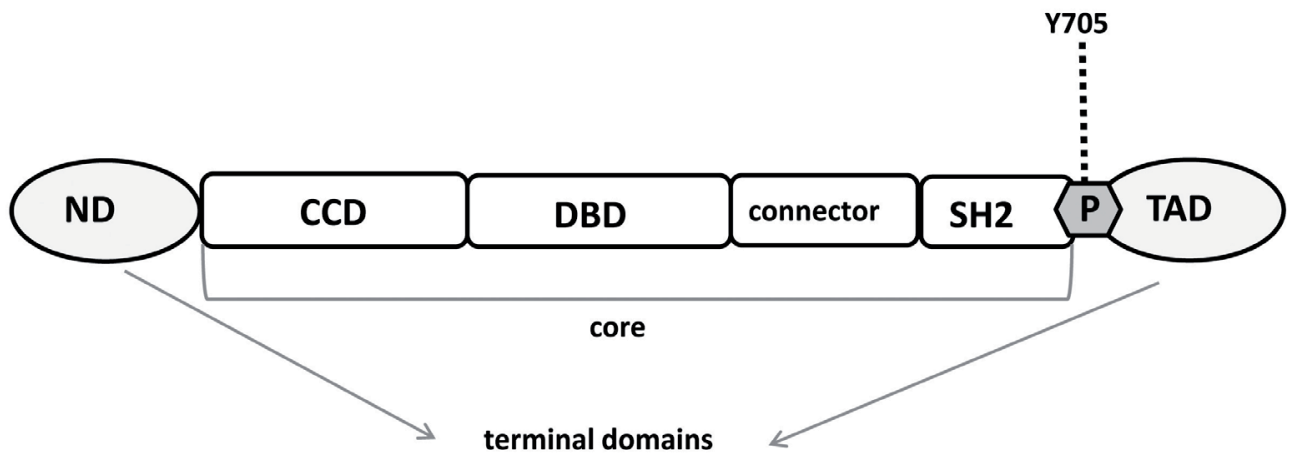

Figure 1. Structure of STAT3 protein. Functional domain: $\mathrm{N}$-terminal domain (ND); coiled-coil domain (CCD); DNA binding domain (DBD); Src homology domain (SH2); C-terminal transcriptional activation domain (TAD). Post-translational modification occurs at the 705-tyrosine site (Y705)

Table 1. The inducers of STAT3

\begin{tabular}{lll}
\multicolumn{1}{c}{ Cyterleukins } & \multicolumn{1}{c}{ Growth factors } \\
\hline IL-6, & - leukaemia inhibitory factor (LIF), & - epidermal growth factor receptor (EGFR), \\
IL-7, & - ciliary neurotrophic factor (CNTF), & - hepatocyte growth factor receptor (HGFR), \\
IL-10, & - interferon y (IFN- y), & - fibroblast growth factor receptor (FGFR), \\
IL-20 & - tumour necrosis factor (TNF-a), & - platelet-derived growth factor receptor (PDGFR), \\
& - monocyte-1 chemotactic protein (MCP-1), & - insulin-like growth factor receptor (IGFR), \\
& - macrophage inflammatory protein-1a (MIP-1a), & - vascular endothelial growth factor receptor \\
& - stem cell factor (SCF), & (VEGFR) \\
& - oncostatin M (OSM) & \\
\hline
\end{tabular}


mTOR phosphorylate STAT3 on S727 in the C-terminal domain [14].

Additionally, STAT3 is also acetylated on a single lysine residue located at position 685 by histone acetyltransferase p300. This acetylation regulates both transcriptional activity and homodimer stability. Other factors, such as UV radiation or sunlight, carcinogen, stress, smoke and infection are also known to play a significant role in STAT3 activation. STAT3 is negatively regulated by specific factors, including the suppressor of cytokine signalling (SOCS) and the protein inhibitor of activated STAT (PIAS) $[15,16]$.

\section{Role of STAT3 in the patho- genesis of colorectal cancer}

CRC cells and normal colon cells differ in their hallmarks. In normal cells, the activation of STAT3 is rapid and transient, whereas, in CRC cells, abnormal activation of STAT3 accelerates CRC cell proliferation, blocks their differentiation and inhibits apoptosis which leads to the occurrence and development of CRC. Several studies showed that STAT3 activation contributes to cellular proliferation and survival in the case of CRC. Persistent activation of STAT3 induces upregulated expression of CyclinD1, c-Myc and survivin and accelerates cell cycle progression in colon cancers [17-19]. The STAT3 signalling pathway suppresses apoptosis in CRC through upregulation of the expression of anti-apoptotic proteins such as Bcl-2 (B-cell lymphoma-2), Bcl-xl (B-cell lymphoma-2-like 1), and Mcl1 (myeloid cell leukaemia sequence 1 ) to prevent apoptosis of CRC cells [20, 21]. Inversely, inhibition of STAT3 decreases cell proliferation and promotes apoptosis in CRC [22]. Additionally, recent studies have demonstrated that increased phosphorylated STAT3 (phosphoSTAT3) expression was detected in patients with colorectal carcinoma. However, the prognostic value and clinicopathological parameters of phoshoSTAT3 expression in CRC remain undefined [2].

Tang et al. [23] reported that the positive expression of JAK 1 and STAT3 proteins in patients with colon cancer was not associated with sex, age, tumour differentiation degree and neurovascular invasion, but was dependent on the clinical stage of cancer, tumour infiltration depth and lymph node metastasis. The survival time of CRC patients with positively-expressed JAK1 and STAT3 proteins was significantly shorter compared to patients with negatively-expressed JAK 1 and STAT3. Thus, the JAK/STAT signal may be used as a novel tumour marker and prognostic factor for the diagnosis, assessment and prognosis of colon cancer [23].

STAT3 promotes cell invasion by activating the transcription of matrix metalloproteinases, mainly MMP-2 and MMP-9. In the case of CRC, a correlation between increased MMP-2 and MMP-9 expression and a poor outcome has been proven [24]. Several studies refer to the utility of serum MMPs as markers for CRC invasion. Dragutinović et al. [25] confirmed the higher levels of MMP-2 and MMP-9 proteins in the sera of patients with CRC compared to controls with no CRC. Additionally, Kryczka et al. [26] described the upregulation of MMP-2 expression in invasive CRC. The opposite effect was observed in the case of MMP-12, which is also called metalloelastase, which does not belong to any of the MMP subfamilies. According to the studies in animal and human models, increased MMP-12 expression is associated with both reduced tumour growth and increased overall survival $[27,28]$.

STAT3 activation can also contribute to angiogenesis through its effects on vascular endothelial growth factor (VEGF) [29]. However, there is still controversy in terms of the relationship between serum VEGF and VEGF receptor (VEGF-R) tumour expression in CRC [30]. Evidence from preclinical and clinical studies indicates that VEGF is the predominant angiogenic factor in human CRC and is associated with the formation of metastases and poor prognosis [31].

The JAK/STAT/SOCS-signalling pathway plays a critical role in immune response and regulation of inflammation. Additionally, components of the pathway, such as STAT3, have been shown to promote cell growth and survival through impairment of the expression of genes involved in apoptosis, cell cycle regulation and angiogenesis [32]. SOCS3 is an important signal inhibition factor in the JAK2/STAT3 pathway. The reduction or deletion of SOCS3 expression causes sustained activation of STAT3 in many malignant tumours [33]. Other studies indicate that posphoSTAT3 in $\mathrm{CRC}$ is higher than in surrounding tissues, whereas the expression of SOCS3 is lower or absent in CRC tissues. The activation of this signalling 
pathway promotes the transformation of colitis to CRC. SOCS3 protein inhibited the activation of the JAK/STAT3 pathway by negative feedback regulation of tyrosine phosphorylation of STAT3, which inhibits the growth of tumour cells. STAT3 activation also promoted hypermethylation of SOCS3 gene promoters in DLD1, HT-29 and SW480 cancer cells [34].

\section{STAT3 as a target in CRC therapy}

As STAT3 plays an important role in the development of CRC, it could be used as an essential target in the diagnosis and treatment of CRC. These inhibitors are not implemented in clinical practice but are suggested to be useful. However, clinical studies are required to assess their usefulness, efficiency and potential anticancer activities.

Table 2 presents the chemical structure of potential inhibitors of STAT3. In this review, we focus on the representatives of different groups of compounds possessing the possible implications of targeting STAT3 in colon cancer. Moreover, the mechanism of STAT3activation is multifaced, thus Figure 2 presents the suggested therapeutic intervention strategy in the STAT3 pathway during CRC therapy.

Nowadays, STAT3 inhibitors can be classified as indirect and direct (Table 2). The indirect strategy can block molecules and induce the STAT3 pathway, indirectly inhibiting the signal transduction functions of STAT3, mostly through inhibiting the function of JAKs, in turn, there are sev-

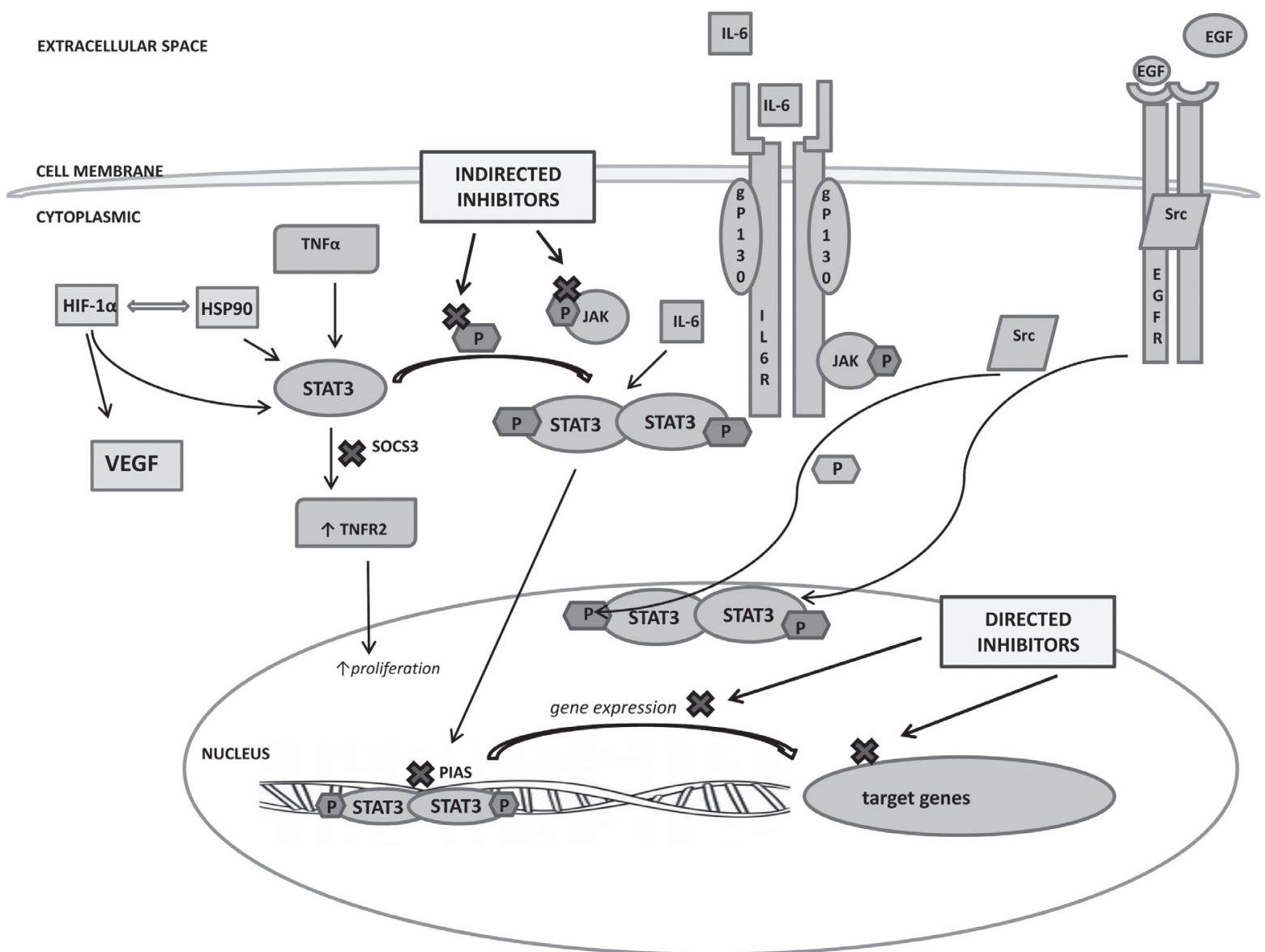

Figure 2. Therapeutic intervention strategy in the STAT3 signalling pathway for CRC therapy. Under physiological conditions, STAT3 is localised in the cytoplasm and nucleus and can be activated by IL- 6 and other cytokines, including TNF-a. In response to stimulation of STAT3 by cytokines, JAK1 is usually involved in the dimerisation of STAT3, as well as nuclear transport and binding to DNA. Growth factors, like EGFR, VEGFR, and non-receptor tyrosine kinases (Src) can also stimulate STAT3. Activation of STAT3 is controlled by inhibitors of cytokine signalling (SOCS) and protein inhibitors of active STAT, protein inhibitors of activated STAT (PIAS). Signal transduction is initiated by dimerisation of glycoprotein 130 (gp130) due to the effect of growth factor or interleukin [36]. The activation of STAT3 can also be dependent on the functionality of the hypoxia-inducible factor 1-a (HIF-1a). Both STAT3 and HIF-1a are heat shock protein 90 (HSP90) client proteins, which transcribe VEGF [37], EGF, IL-6R and TNF2 
Table 2. Inhibitors of STAT3

\section{INDIRECT INHIBITORS OF STAT3}

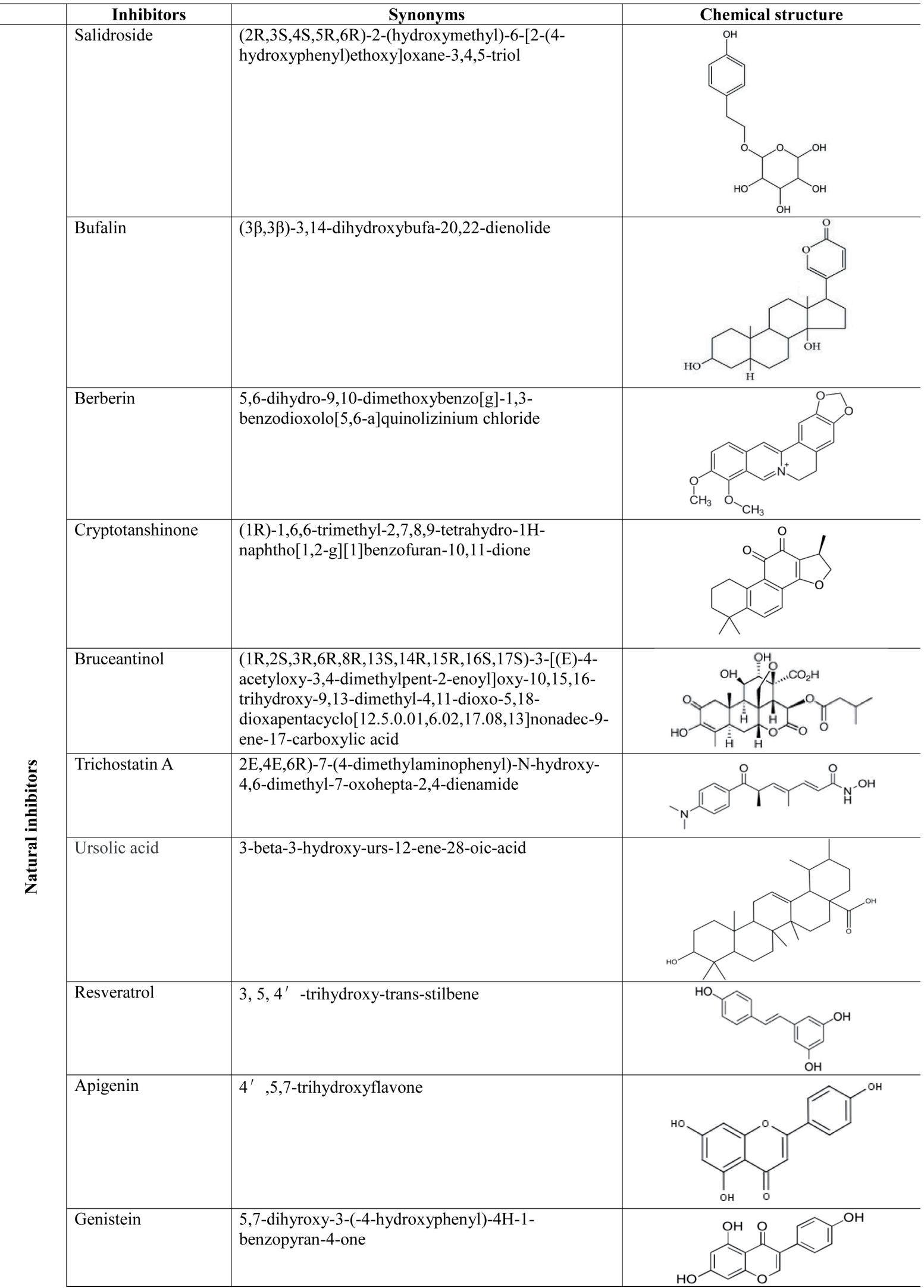


Table 2. Continued

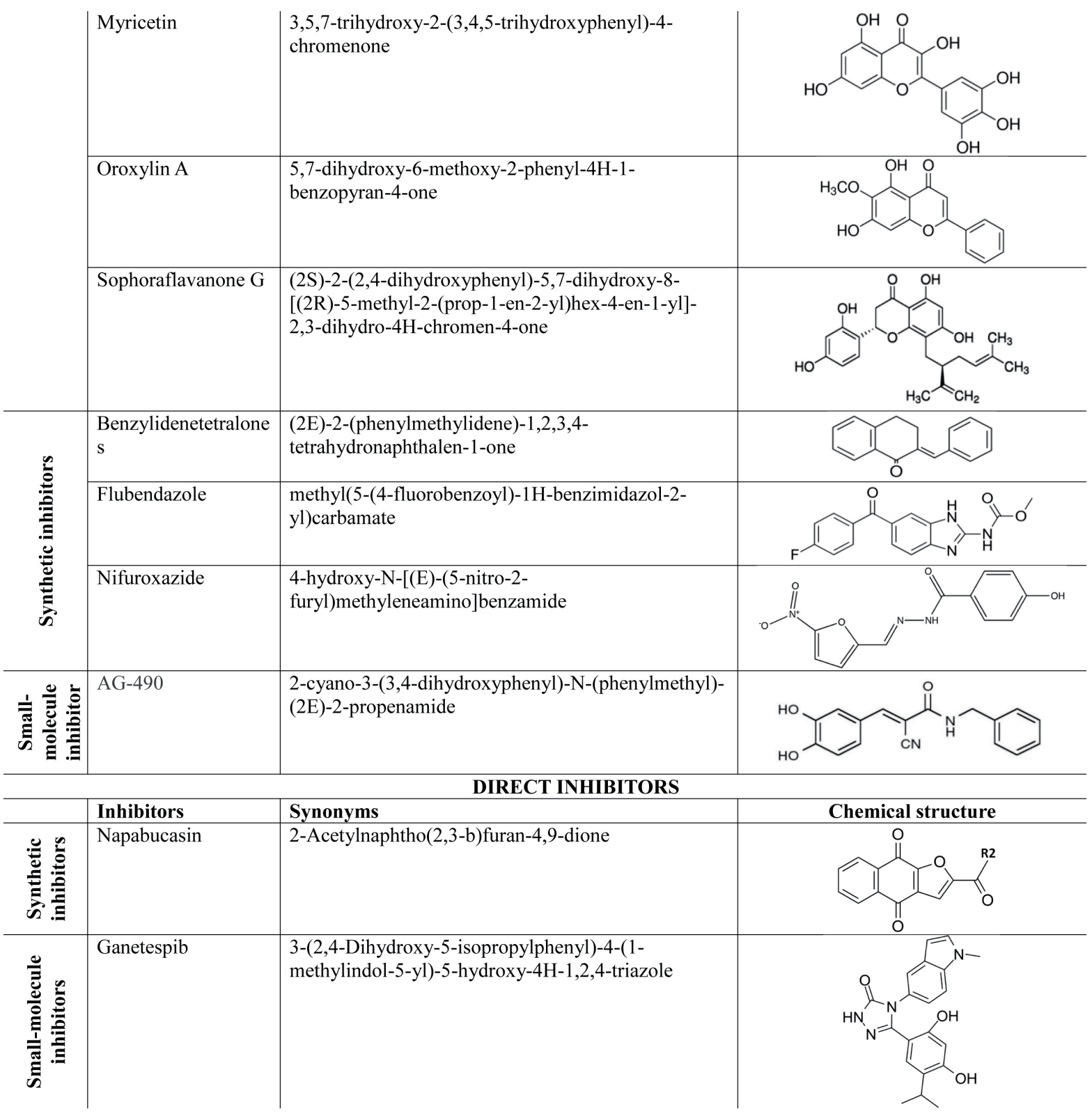

eral direct strategies according to different target domains, including the $\mathrm{SH} 2$ domain [35-37].

\section{Indirect inhibitors}

\section{Natural inhibitors}

Salidroside is a glucoside extracted from Rhodiola rosea [38], which inhibits the proliferation and cell cycle and reduces migration and invasion of colon cancer SW1116 cells through blocking the phosphorylation of JAK/STAT3 [39]. Moreover, Li and Chen [2017] suggest that salidroside downregulates phosphoSTAT3 in HCT116 cells, which is correlated with the induction of autophagy.

Bufalin is a steroid isolated from Chinese toad venom, which inhibits JAK/STAT3 signalling through decreasing the level of phosphoSTAT3 and downregulates the $\mathrm{Bcl}-2$ protein. Bufalin blocks the proliferation of colon adenocarcinoma SW620 cells and induces $\mathrm{G} 2 / \mathrm{M}$ cell cycle arrest of these cells $[40,41]$. Similar results were reported by Qiu et al. [42], that bufalin reduces the viability of HCT116 cells in a dose- and time-dependent manner. 
Berberin is an alkaloid isolated from Hydrastis canadensis and can decrease phosphorylation of JAK and STAT3 proteins in CRC cells [43]. Other studies demonstrated that berberin affects the expression of MMP-2 and MMP-9, but the mechanism has not been elucidated $[44,45]$. Liu et al. [43] argue that berberin reduces COX-2/PGE2 levels, consequently decreasing JAK2/STAT3 activation, leading to dampened expression of downstream target genes MMP-2 and MMP-9, reducing invasiveness and metastasis in CRC. A similar effect was presented by $\mathrm{Hu}$ et al. [46] and Hallajzadeh et al. [47], where the reduction in the JAK2/STAT3 signalling as a consequence of attenuating the COX-2/PGE2 expression by berberin was observed.

Cryptotanshinone is a quinoid diterpene isolated from Salvia miltiorrhiza Bunge. It inhibits the activation of STAT3 pathways through inactivating phosphorylation of STAT3 in SW480, HCT116 and LOVO CRC cell lines. Moreover, cryptotanshinone attenuates the expression of $\mathrm{BCl}-2$, CyclinD1 and survivin in HCT116 and SW480 cells. The mechanism of action of cryptotanshinone by direct interaction with STAT3 can also rely on the inhibition of EGFR phosphorylation at higher doses of cryptotanshinone [48].

Bruceantinol is a triterpenoid isolated from Brucinea javanica, which reduces the level of phosphorylated STAT3 and downstream target expression of $\mathrm{Mcl}-1, \mathrm{C}-\mathrm{Myc}$, and survivin in vitro. A reduction of phosphoSTAT3 was observed in mice with CRC xenografts treated with bruceantinol [49].

Trichostatin A is a hydroxamic acid produced by Streptomyces hygroscopicus and an inhibitor of class I and II histone deacetylases. The hyperacetylation of histones is associated with SOCS1 and SOCS3 promoters in CRC cells [50]. According to Xiong et al. [50], trichostatin A can increase the level of SOCS1 and SOCS3 expression in SW1116 and HT-29 colon cancer cell lines. Consequently, it negatively modulates the JAK2/ STAT3 pathway, subsequently downregulating $\mathrm{Bcl}-2$ and survivin and decreases growth and apoptosis of CRC cells.

Ursolic acid is a pentacyclic triterpenoid, abundant in apples, pears and prunes [51]. Studies conducted by Wang et al. [52] confirmed that ursolic acid selectively inhibits STAT3 phosphorylation at Y705 in CRC cell lines, HT-29, HCT116 and SW480. Moreover, some studies confirmed the antiapoptotic properties of ursolic acid in HT-29 cells via inhibition of $\mathrm{Bcl}-\mathrm{xl}, \mathrm{Bcl}-2$ and Cyclin D1 expression [53, 54].

Resveratrol is a plant polyphenol naturally occurring in grapes, red wine, and peanuts [55]. It can inhibit cell proliferation and promote cell apoptosis via the STAT3 signalling pathway in DLD1 and HCT15 colon cancer cells. Li et al. [56] demonstrated that resveratrol inhibits cell growth in CRC by inhibiting the serine/threonine-protein kinase AKT and its downstream signalling targets. AKT serves as an upstream regulator of STAT3. Additionally, the expression of phosphorylation of STAT3 at the Tyr705 site was suppressed by treatment with resveratrol in a dosedependent manner [56].

Apigenin is a type of flavone identified in several types of berries and vegetables, which inhibits the nuclear localisation of STAT3 through the reduction of the expression of phosphoSTAT3 (Tyr705) in HCT116 colon cancer cells [57].

Genistein is a major isoflavone in soy and soybased food products that are regularly consumed in Asian countries [58]. Genistein promotes apoptosis in HT-29 colon cancer cells by modulating caspase- 3 and p38 MAPK signalling pathway [59]. Genistein also abolished the activation of STAT3, preventing translocation into the nucleus by downregulating the activity of JNK [60].

Myricetin is a common dietary flavonoid abundantly found in plants. It deregulates the JAK1/STAT3 signalling pathway that controls many processes such as cell growth, differentiation, senescence and apoptosis [61]. Myricetin directly binds with the catalytic domain of the JAK 1 protein and inhibits the phosphorylation of STAT3 and JAK1. Moreover, myricetin has been found to increase EGF-induced autophosphorylation of EGFR at Tyr845, Tyr992, Tyr1045, Tyr1068, and Tyr1173, as well as inhibit the autophosphorylation of endogenous EGFR sites. The results indicated that myricetin exerts its chemopreventive effect by directly interacting with JAK1 and STAT3 proteins [62].

Oroxylin A is an O-methylated flavone found in the roots of Scutellaria baicalensis. It inhibits colitis-associated carcinogenesis through modulating the IL-6/STAT3 pathway in AOM/ DSS mouse model and HCT116 cells. This study confirmed that oroxylin A induces $\mathrm{Bax}$ and $\mathrm{Bcl}-2$ binding in colon cancer Caco-2 cells [57]. 
Sophoraflavanone $\mathbf{G}$ is a plant material isolated from Sophora leachiana, S. exigua or S. moorcroftiana. S. pachycarpa or S. flavescens. Treatment of HCT116 cells with this small-molecule significantly inhibited tyrosine phosphorylation of STAT3, as confirmed by western blot analysis, where the level of phosphoSTAT3 protein was decreased in comparison to the control [63].

The ethanol extract of Prunella vulgaris L., termed Spica Prunellae, is a well-known traditional Chinese formulation, which can inhibit the STAT3 phosphorylation of $Y 705$, increase the $\mathrm{Bax} / \mathrm{Bcl}-2$ ratio, reduce Cyclin D1 and subsequently inhibit $\mathrm{CRC}$ cell proliferation and promote apoptosis [64-66].

\section{Synthetic inhibitors}

Benzylidenetetralones are synthetic, cyclic chalcone analogues [67]. Natural and synthetic chalcones have also shown anticancer activity caused by their inhibitory potential against targets such as the JAK/STAT signalling pathway [68]. Benzylidenetetralones decrease the expression of $\mathrm{Bcl}-\mathrm{xl}$, consequently inducing cell cycle arrest and apoptosis in the HCT116 CRC cell line [67].

Flubendazole is a well-known anthelmintic drug, which blocks IL6-induced nuclear translocation of STAT3, leading to the inhibition of the transcription of STAT3 target genes, such as MCL1 and VEGF. Flubendazole inhibition of STAT3 phosphorylation is partly dependent on the upstream kinases JAK2 and JAK3. Also, flubendazole reduces the expression of $P-m T O R$, $P 62, \mathrm{BCl}-2$, and upregulates Beclin1 and LC3-I/II, major autophagy-related genes, thereby inducing potent cell apoptosis in CRC cells. Furthermore, flubendazole displays a synergistic effect with the chemotherapeutic agent 5 -fluorouracil in the treatment of CRC [69].

Nifuroxazide is a nifuran antibiotic, which downregulates the phosphorylation of tyrosine residues (Y705) on STAT3 as well as impairing the expression of MMP-2 and MMP-9 in HCT116 and HT-29 human CRC cell lines [70].

\section{Small-molecule inhibitors}

AG-490 is a pharmacological inhibitor of kinase JAK2, which decreases VEGF secretion in SW1116 and HT-29 cells, functioning likes the JAK/STAT3 pathway in angiogenesis [71]. Additionally, the downregulation of phosphoJAK1, phosphoJAK2 and
phosphoSTAT3 was observed after treatment with AG490. This leads to a decline in Bcl-2 and survivin expression [71,72]. Furthermore, STAT3 inhibition by AG-490 treatment has been found to increase cell sensitivity to chemotherapeutic agents [73].

\section{Direct inhibitors}

\section{Natural inhibitors}

Curcumin is a natural polyphenol, the yellow pigment in Curcuma longa L. It reduces binding of STAT3 to DNA in CRC cells [74], thereby abrogating its phosphorylation and nuclear translocation, as well as the subsequent expression of target genes. This approach has mainly focused on targeting the $\mathrm{SH} 2$ domain, an important domain by which STAT3 maintains its biological functions [75].

\section{Synthetic inhibitors}

Napabucasin was the first compound to undergo a series of clinical trials (NCT03522649, NCT02753127, NCT01776307, NCT02851004, NCT01830621, NCT02641873) to determine its efficacy and safety in patients with metastatic CRC [76]. A napabucasin derivative with a 2-(piperidin1-yl)ethylamino-group substituted at the R2 position significantly inhibited tumour growth in a mouse model. Molecular docking suggested that this compound bound to the SH2 domain of STAT3 in CT26 colon carcinoma mouse cell line [77].

\section{Small-molecule inhibitors}

Ganetespib is a small-molecule inhibitor of heat shock protein 90 (HSP90) activity. Ganji et al. [78] demonstrated that ganetespib inhibits STAT3 and disrupts angiogenesis of CRC cell lines HCT116 and $\mathrm{HT}-29$, also downregulating the expression of VEGF transcription factors, hypoxia-inducible factor 1-a (HIF-1a) and STAT3. Both STAT3 and HIF-1a are dependent on HSP90 and transcribe VEGF, therefore, HSP90 inhibition by ganetespib also affects the expression of HIFla and STAT3, leading to decreased transcription of pro-angiogenic cytokines such as VEGF in CRC [79].

\section{Conclusions}

STAT3 is an important signal transducer and activator of transcription which is widely involved 
in numerous cellular physiological processes, such as proliferation, differentiation and apoptosis. Available data indicate that STAT3 is involved in the pathogenesis of colorectal cancer, hence, it may be useful in colorectal cancer diagnosis, treatment and prognosis. However, further studies are needed to determine if STAT3 is of use in cancer diagnosis and prognosis of disease development, as well as the possible beneficial effects of STAT3 targeted therapy. There is an increasing evidence STAT3 inhibitors, such as phytochemicals or synthetic compounds, may be potential therapeutics for colorectal cancer, so further research regarding the inhibitory properties of natural or synthetic compounds is justified.

\section{Acknowledgements}

\section{Conflict of interest statement}

The authors declare no conflict of interest.

\section{Funding sources}

There are no sources of funding to declare.

\section{References}

1. Dekker E, Tanis PJ, Vleugels JLA, Kasi PM, Wallace MB. Colorectal cancer. The Lancet. 2019 Oct;394(10207):1467-1480. https://doi.org/10.1016/ s0140-6736(19)32319-0

2. Ji K, Zhang $M$, Chu $Q$, Gan $Y$, Ren $H$, Zhang L, Wang L, Li X, Wang W. The Role of p-STAT3 as a Prognostic and Clinicopathological Marker in Colorectal Cancer: A Systematic Review and Meta-Analysis. Shi X. PLOS ONE. 2016 Aug 9;11(8):e0160125. https://doi. org/10.1371/journal.pone.0160125

3. Fearon ER, Vogelstein B. A genetic model for colorectal tumorigenesis. Cell. 1990 Jun;61(5):759-767. https://doi.org/10.1016/0092-8674(90)90186-i Wake MS, Watson CJ. STAT3 the oncogene - still eluding therapy?. FEBS Journal. 2015 Apr 22;282(14):26002611. https://doi.org/10.1111/febs. 13285

4. Laudisi F, Cherubini F, Di Grazia A, Dinallo V, Di Fusco D, Franzè E, Ortenzi A, Salvatori I, Scaricamazza S, Monteleone I, Sakamoto N, Monteleone G, Stolfi C. Progranulin sustains STAT 3 hyper activation and oncogenic function in colorectal cancer cells. Molecular Oncology. 2019 Aug 10;13(10):2142-2159. https:// doi.org/10.1002/1878-0261.12552

5. Xiong A, Yang Z, Shen Y, Zhou J, Shen Q. Transcription Factor STAT3 as a Novel Molecular Target for Cancer Prevention. Cancers. 2014 Apr 16;6(2):926957. https://doi.org/10.3390/cancers6020926

6. Yu H, Lee H, Herrmann A, Buettner R, Jove R. Revisiting STAT3 signalling in cancer: new and unexpected biological functions. Nature Reviews Cancer. 2014 Oct 24;14(11):736-746. https://doi.org/10.1038/ nrc3818
7. Grivennikov SI, Greten FR, Karin M. Immunity, Inflammation, and Cancer. Cell. 2010 Mar;140(6):883-899. https://doi.org/10.1016/j.cell.2010.01.025

8. Shi Y, Zhang Z, Qu X, Zhu X, Zhao L, Wei R, Guo Q, Sun $L$, Yin X, Zhang Y, Li X. Roles of STAT3 in leukemia (Review). International Journal of Oncology. $2018 \mathrm{Apr}$ 30;. https://doi.org/10.3892/ijo.2018.4386

9. Xin P, Xu X, Deng C, Liu S, Wang Y, Zhou X, Ma H, Wei $D$, Sun $S$. The role of JAK/STAT signaling pathway and its inhibitors in diseases. International Immunopharmacology. 2020 Mar;80:106210. https://doi. org/10.1016/j.intimp.2020.106210

10. Pilati C, Zucman-Rossi J. Mutations leading to constitutive active gp130/JAK1/STAT3 pathway. Cytokine \& Growth Factor Reviews. 2015 Oct;26(5):499-506. https://doi.org/10.1016/j.cytogfr.2015.07.010

11. Bournazou E, Bromberg J. Targeting the tumor microenvironment. JAK-STAT. 2013 Apr;2(2):e23828. https://doi.org/10.4161/jkst.23828

12. Bowman T, Garcia R, Turkson J, Jove R. STATs in oncogenesis. Oncogene. 2000 May;19(21):24742488. https://doi.org/10.1038/sj.onc. 1203527

13. Kim B, Yi EH, Ye S. Signal transducer and activator of transcription 3 as a therapeutic target for cancer and the tumor microenvironment. Archives of Pharmacal Research. 2016 Aug;39(8):1085-1099. https:// doi.org/10.1007/s12272-016-0795-8

14. Monique C T, Alister C W. SoCS proteins in development and disease. Am J Clin Exp Immunol. 2013 Feb 27;2(1):1-29. PMID 23885323

15. Shuai $K$. Regulation of cytokine signaling pathways by PIAS proteins. Cell Research. 2006 Feb;16(2):196202. https://doi.org/10.1038/sj.cr.7310027

16. Horiguchi A, Oya M, Marumo K, Murai M. STAT3, but not ERKs, mediates the IL-6-induced proliferation of renal cancer cells, ACHN and 769P. Kidney International. 2002 Mar;61(3):926-938. https://doi. org/10.1046/j.1523-1755.2002.00206.x

17. Corvinus FM, Orth $C$, Moriggl R, Tsareva SA, Wagner S, Pfitzner EB, Baus D, Kaufman R, Huber LA, Zatloukal K, Beug H, Öhlschläger P, Schütz A, Halbhuber $\mathrm{K}$, Friedrich K. Persistent STAT3 Activation in Colon Cancer Is Associated with Enhanced Cell Proliferation and Tumor Growth. Neoplasia. 2005 Jun;7(6):545555. https://doi.org/10.1593/neo.04571

18. Lin L, Liu A, Peng Z, Lin H, Li P, Li C, Lin J. STAT3 Is Necessary for Proliferation and Survival in Colon Cancer-Initiating Cells. Cancer Research. 2011 Sep 7;71(23):7226-7237. https://doi.org/10.1158/00085472.can-10-4660

19. Catlett-Falcone R, Landowski TH, Oshiro MM, Turkson J, Levitzki A, Savino R, Ciliberto G, Moscinski L, Fernández-Luna JL, Nuñez G, Dalton WS, Jove R. Constitutive Activation of Stat3 Signaling Confers Resistance to Apoptosis in Human U266 Myeloma Cells. Immunity. 1999 Jan;10(1):105-115. https://doi. org/10.1016/s1074-7613(00)80011-4

20. Epling-Burnette P, Liu JH, Catlett-Falcone R, Turkson J, Oshiro M, Kothapalli R, Li Y, Wang J, YangYen $\mathrm{H}$, Karras J, Jove R, Loughran TP. Inhibition of STAT3 signaling leads to apoptosis of leukemic large granular lymphocytes and decreased $\mathrm{Mcl}-1$ expres- 
sion. Journal of Clinical Investigation. 2001 Feb 1;107(3):351-362. https://doi.org/10.1172/jci9940

21. Lee H, Jeong AJ, Ye S. Highlighted STAT3 as a potential drug target for cancer therapy. BMB Reports. 2019 Jul 31;52(7):415-423. https://doi.org/10.5483/ bmbrep.2019.52.7.152

22. Tang S, Yuan X, Song J, Chen Y, Tan X, Li Q. Association analyses of the JAK/STAT signaling pathway with the progression and prognosis of colon cancer. Oncology Letters. 2018 Oct 12;. https://doi. org/10.3892/ol.2018.9569

23. Said A, Raufman J, Xie G. The Role of Matrix Metalloproteinases in Colorectal Cancer. Cancers. 2014 Feb 10;6(1):366-375. https://doi.org/10.3390/cancers6010366

24. Dragutinović VV, Radonjić NV, Petronijević ND, Tatić SB, Dimitrijević IB, Radovanović NS, Krivokapić ZV. Matrix metalloproteinase-2 (MMP-2) and -9 (MMP-9) in preoperative serum as independent prognostic markers in patients with colorectal cancer. Molecular and Cellular Biochemistry. 2011 May 4;355(1-2):173178. https://doi.org/10.1007/s11010-011-0851-0

25. Kryczka J, Stasiak M, Dziki L, Mik M, Dziki A, Cierniewski CS. Matrix Metalloproteinase-2 Cleavage of the $\beta 1$ Integrin Ectodomain Facilitates Colon Cancer Cell Motility. Journal of Biological Chemistry. 2012 Aug 16;287(43):36556-36566. https://doi.org/10.1074/ jbc.m112.384909

26. Xu Z, Shi H, Li Q, Mei Q, Bao J, Shen Y, Xu J. Mouse macrophage metalloelastase generates angiostatin from plasminogen and suppresses tumor angiogenesis in murine colon cancer. Oncology Reports. 2008 Jul 1;. https://doi.org/10.3892/or.20.1.81

27. Yang W, Arii S, Gorrin-Rivas M, Mori A, Onodera H, Imamura M. Human macrophage metalloelastase gene expression in colorectal carcinoma and its clinicopathologic significance. Cancer. 2001 Apr 1;91(7):1277-83. PMID 11283927

28. Goulart A, Ferreira C, Rodrigues A, Coimbra B, Sousa $N$, Leão $P$. The correlation between serum vascular endothelial growth factor (VEGF) and tumor VEGF receptor 3 in colorectal cancer. Annals of Surgical Treatment and Research. 2019;97(1):15. https://doi. org/10.4174/astr.2019.97.1.15

29. Tsai H, Yang I, Lin C, Chai C, Huang Y, Chen C, Hou M, Kuo C, Juo S, Wang J. Predictive value of vascular endothelial growth factor overexpression in early relapse of colorectal cancer patients after curative resection. International Journal of Colorectal Disease. 2012 Sep 9;28(3):415-424. https://doi. org/10.1007/s00384-012-1570-z Guba M, Seeliger H, Kleespies A, Jauch K, Bruns C. Vascular endothelial growth factor in colorectal cancer. International Journal of Colorectal Disease. 2004 Mar 4;19(6):510517. https://doi.org/10.1007/s00384-003-0576-y

30. Slattery ML, Lundgreen A, Kadlubar SA, Bondurant KL, Wolff RK. JAK/STAT/SOCS-signaling pathway and colon and rectal cancer. Molecular Carcinogenesis. 2011 Nov 28;52(2):155-166. https://doi. org/10.1002/mc. 21841
31. Inagaki-Ohara $K$, Kondo $T$, Ito $M$, Yoshimura $A$. SOCS, inflammation, and cancer. JAK-STAT. $2013 \mathrm{Jul}$ 15;2(3):e24053. https://doi.org/10.4161/jkst.24053

32. Matsumoto $S$, Hara T, Mitsuyama K, Yamamoto $M$, Tsuruta O, Sata M, Scheller J, Rose-John S, Kado S, Takada T. Essential Roles of IL-6Trans-Signaling in Colonic Epithelial Cells, Induced by the IL-6/Soluble-IL-6 Receptor Derived from Lamina Propria Macrophages, on the Development of Colitis-Associated Premalignant Cancer in a Murine Model. The Journal of Immunology. 2009 Dec 30;184(3):1543-1551. https://doi.org/10.4049/jimmunol.0801217

33. Siveen KS, Sikka S, Surana R, Dai X, Zhang J, Kumar AP, Tan BK, Sethi G, Bishayee A. Targeting the STAT3 signaling pathway in cancer: Role of synthetic and natural inhibitors. Biochimica et Biophysica Acta (BBA) - Reviews on Cancer. 2014 Apr;1845(2):136154. https://doi.org/10.1016/j.bbcan.2013.12.005

34. Xu Q, Briggs J, Park S, Niu G, Kortylewski M, Zhang S, Gritsko T, Turkson J, Kay H, Semenza GL, Cheng JQ, Jove R, Yu H. Targeting Stat3 blocks both HIF-1 and VEGF expression induced by multiple oncogenic growth signaling pathways. Oncogene. 2005 Jun 20;24(36):5552-5560. https://doi.org/10.1038/ sj.onc. 1208719

35. Chen Q, Lv J, Yang W, Xu B, Wang Z, Yu Z, Wu J, Yang $Y$, Han $Y$. Targeted inhibition of STAT3 as a potential treatment strategy for atherosclerosis. Theranostics. 2019;9(22):6424-6442. https://doi.org/10.7150/ thno.35528

36. Fan X, Wang $Y$, Wang L, Zhu M. Salidroside induces apoptosis and autophagy in human colorectal cancer cells through inhibition of PI3K/Akt/mTOR pathway. Oncology Reports. 2016 Sep 30;36(6):35593567. https://doi.org/10.3892/or.2016.5138

37. Kuan-Xue S, Hong-Wei X, Rong-Long X. Anticancer effect of salidroside on colon cancer through inhibiting JAK2/STAT3 signaling pathway. Int J Clin Exp Pathol. 2015;8(1):615-21. PMID 25755753

38. Zhu Z, Sun H, Ma G, Wang Z, Li E, Liu Y, Liu Y. Bufalin Induces Lung Cancer Cell Apoptosis via the Inhibition of PI3K/Akt Pathway. International Journal of Molecular Sciences. 2012 Feb 14;13(2):2025-2035. https://doi.org/10.3390/ijms13022025

39. Wang S, Sun Y. The IL-6/JAK/STAT3 pathway: Potential therapeutic strategies in treating colorectal cancer. International Journal of Oncology. 2014 Jan 15;44(4):1032-1040. https://doi.org/10.3892/ ijo.2014.2259

40. Qiu Y, Hu Q, Tang Q, Feng W, Hu S, Liang B, Peng W, Yin P. MicroRNA-497 and bufalin act synergistically to inhibit colorectal cancer metastasis. Tumor Biology. 2013 Dec 29;35(3):2599-2606. https://doi. org/10.1007/s13277-013-1342-6

41. Liu X, Ji Q, Ye N, Sui H, Zhou L, Zhu H, Fan Z, Cai J, Li Q. Berberine Inhibits Invasion and Metastasis of Colorectal Cancer Cells via COX-2/PGE2 Mediated JAK2/STAT3 Signaling Pathway. Tang C. PLOS ONE. 2015 May 8;10(5):e0123478. https://doi.org/10.1371/ journal.pone.0123478

42. Kuo $\mathrm{H}$, Chuang $\mathrm{T}$, Tsai $\mathrm{S}$, Tseng $\mathrm{H}$, Hsu $\mathrm{S}$, Chen $\mathrm{Y}$, Kuo C, Kuo Y, Liu J, Kao M. Berberine, an Isoquin- 
oline Alkaloid, Inhibits the Metastatic Potential of Breast Cancer Cells via Akt Pathway Modulation. Journal of Agricultural and Food Chemistry. 2012 Sep 14;60(38):9649-9658. https://doi.org/10.1021/ jf302832n

43. Hamsa TP, Kuttan G. Berberine Inhibits Pulmonary Metastasis through Down-regulation of MMP in Metastatic B16F-10 Melanoma Cells. Phytotherapy Research. 2011 Sep 26;26(4):568-578. https://doi. org/10.1002/ptr.3586

44. Hu S, Zhao R, Liu Y, Chen J, Zheng Z, Wang S. Preventive and Therapeutic Roles of Berberine in Gastrointestinal Cancers. BioMed Research International. 2019 Dec 28;2019:1-10. https://doi. org/10.1155/2019/6831520

45. Hallajzadeh J, Maleki Dana P, Mobini M, Asemi Z, Mansournia MA, Sharifi M, Yousefi B. Targeting of oncogenic signaling pathways by berberine for treatment of colorectal cancer. Medical Oncology. 2020 Apr 17;37(6). https://doi.org/10.1007/s12032-02001367-9

46. Li W, Saud SM, Young MR, Colburn NH, Hua B. Cryptotanshinone, a Stat3 inhibitor, suppresses colorectal cancer proliferation and growth in vitro. Molecular and Cellular Biochemistry. 2015 Apr 26;406(1-2):63-73. https://doi.org/10.1007/s11010-015-2424-0

47. Wei N, Li J, Fang C, Chang J, Xirou V, Syrigos NK, Marks BJ, Chu E, Schmitz JC. Targeting colon cancer with the novel STAT3 inhibitor bruceantinol. Oncogene. 2018 Oct 22;38(10):1676-1687. https://doi. org/10.1038/s41388-018-0547-y

48. Xiong $\mathrm{H}$, Du W, Zhang $\mathrm{Y}$, Hong J, Su W, Tang J, Wang Y, Lu R, Fang J. Trichostatin A, a histone deacetylase inhibitor, suppresses JAK2/STAT3 signaling via inducing the promoter-associated histone acetylation of SOCS1 and SOCS3 in human colorectal cancer cells. Molecular Carcinogenesis. $2011 \mathrm{Apr}$ 22;51(2):174-184. https://doi.org/10.1002/mc.20777

49. Kashyap D, Tuli HS, Sharma AK. Ursolic acid (UA): A metabolite with promising therapeutic potential. Life Sciences. 2016 Feb;146:201-213. https://doi. org/10.1016/j.lfs.2016.01.017

50. Wang W, Zhao C, Jou D, Lü J, Zhang C, Lin L, Lin J. Ursolic acid inhibits the growth of colon cancer-initiating cells by targeting STAT3. Anticancer Res. 2013 Oct;33(10):4279-84. PMID 24122993

51. Shan J, Xuan Y, Zheng S, Dong Q, Zhang S. Ursolic acid inhibits proliferation and induces apoptosis of HT-29 colon cancer cells by inhibiting the EGFR/ MAPK pathway. Journal of Zhejiang University SCIENCE B. 2009 Aug 30;10(9):668-674. https://doi. org/10.1631/jzus.b0920149

52. LIN J, CHEN Y, WEI L, SHEN A, SFERRA TJ, HONG Z, PENG J. Ursolic acid promotes colorectal cancer cell apoptosis and inhibits cell proliferation via modulation of multiple signaling pathways. International Journal of Oncology. 2013 Jul 26;43(4):1235-1243. https://doi.org/10.3892/ijo.2013.2040

53. Aluyen JK, Ton QN, Tran T, Yang AE, Gottlieb HB, Bellanger RA. Resveratrol: Potential as Anticancer Agent. Journal of Dietary Supplements. 2012 Feb
14;9(1):45-56. https://doi.org/10.3109/19390211.201 1.650842

54. Li D, Wang G, Jin G, Yao K, Zhao Z, Bie L, Guo Y, Li N, Deng W, Chen X, Chen B, Liu Y, Luo S, Guo Z. Resveratrol suppresses colon cancer growth by targeting the AKT/STAT3 signaling pathway. International Journal of Molecular Medicine. 2018 Nov 1; https:// doi.org/10.3892/ijmm.2018.3969

55. Chae H, Xu R, Won J, Chin Y, Yim H. Molecular Targets of Genistein and Its Related Flavonoids to Exert Anticancer Effects. International Journal of Molecular Sciences. 2019 May 16;20(10):2420. https://doi. org/10.3390/ijms20102420

56. Ronis MJJ. Effects of soy containing diet and isoflavones on cytochrome P450 enzyme expression and activity. Drug Metabolism Reviews. $2016 \mathrm{Jul}$ 2;48(3):331-341. https://doi.org/10.1080/03602532. 2016.1206562

57. Shafiee G, Saidijam M, Tavilani H, Ghasemkhani N, Khodadadi I. Genistein Induces Apoptosis and Inhibits Proliferation of HT29 Colon Cancer Cells. International Journal of Molecular and Cellular Medicine. 2016 Jul;5(3). https://doi.org/10.22088/acadpub. BUMS.5.3.178

58. Tuli HS, Tuorkey MJ, Thakral F, Sak K, Kumar M, Sharma AK, Sharma U, Jain A, Aggarwal V, Bishayee A. Molecular Mechanisms of Action of Genistein in Cancer: Recent Advances. Frontiers in Pharmacology. 2019 Dec 6;10. https://doi.org/10.3389/ fphar.2019.01336

59. Devi KP, Rajavel T, Habtemariam S, Nabavi SF, Nabavi SM. Molecular mechanisms underlying anticancer effects of myricetin. Life Sciences. 2015 Dec;142:1925. https://doi.org/10.1016/j.lfs.2015.10.004

60. Kumamoto T, Fujii M, Hou D. Myricetin directly targets JAK1 to inhibit cell transformation. Cancer Letters. 2009 Mar;275(1):17-26. https://doi.org/10.1016/j. canlet.2008.09.027

61. Kim B, Won C, Lee Y, Choi JS, Noh KH, Han S, Lee H, Lee CS, Lee D, Ye S, Kim M. Sophoraflavanone G induces apoptosis of human cancer cells by targeting upstream signals of STATs. Biochemical Pharmacology. 2013 Oct;86(7):950-959. https://doi. org/10.1016/j.bcp.2013.08.009

62. Lin W, Zheng L, Zhuang Q, Zhao J, Cao Z, Zeng J, Lin $\mathrm{S}, \mathrm{Xu}$ W, Peng J. Spica prunellae promotes cancer cell apoptosis, inhibits cell proliferation and tumor angiogenesis in a mouse model of colorectal cancer via suppression of stat3 pathway. BMC Complementary and Alternative Medicine. 2013 Jun 24;13(1). https:// doi.org/10.1186/1472-6882-13-144

63. Peng J. Pien Tze Huang inhibits tumor cell proliferation and promotes apoptosis via suppressing the STAT3 pathway in a colorectal cancer mouse model. International Journal of Oncology. 2012 Jan 3;. https://doi.org/10.3892/ijo.2012.1326

64. Cai Q, Lin J, Wei L, Zhang L, Wang L, Zhan Y, Zeng J, Xu W, Shen A, Hong Z, Peng J. Hedyotis diffusa Willd Inhibits Colorectal Cancer Growth in Vivo via Inhibition of STAT3 Signaling Pathway. International Journal of Molecular Sciences. 2012 May 18;13(5):61176128. https://doi.org/10.3390/ijms13056117 
65. Drutovic D, Chripkova M, Pilatova M, Kruzliak P, Perjesi P, Sarissky M, Lupi M, Damia G, Broggini M, Mojzis J. Benzylidenetetralones, cyclic chalcone analogues, induce cell cycle arrest and apoptosis in HCT116 colorectal cancer cells. Tumor Biology. 2014 Jul 10;35(10):99679975. https://doi.org/10.1007/s13277-014-2289-y

66. Mahapatra DK, Bharti SK, Asati V. Anti-cancer chalcones: Structural and molecular target perspectives. European Journal of Medicinal Chemistry. 2015 Jun;98:69-114. https://doi.org/10.1016/j. ejmech.2015.05.004

67. Lin S, Yang L, Yao Y, Xu L, Xiang Y, Zhao H, Wang L, Zuo Z, Huang X, Zhao C. Flubendazole demonstrates valid antitumor effects by inhibiting STAT3 and activating autophagy. Journal of Experimental \& Clinical Cancer Research. 2019 Jul 8;38(1). https://doi. org/10.1186/s13046-019-1303-z Ye T, Yang F, Zhu Y, Li Y, Lei Q, Song X, Xia Y, Xiong Y, Zhang L, Wang N, Zhao L, Gou H, Xie Y, Yang S, Yu L, Yang L, Wei Y. Inhibition of Stat3 signaling pathway by nifuroxazide improves antitumor immunity and impairs colorectal carcinoma metastasis. Cell Death \& Disease. 2017 Jan 5;8(1):e2534-e2534. https://doi.org/10.1038/ cddis. 2016.452

68. Xiong $\mathrm{H}$, Zhang Z, Tian X, Sun D, Liang Q, Zhang $\mathrm{Y}$, Lu R, Chen $Y$, Fang J. Inhibition of JAK1, 2/STAT3 Signaling Induces Apoptosis, Cell Cycle Arrest, and Reduces Tumor Cell Invasion in Colorectal Cancer Cells. Neoplasia. 2008 Mar;10(3):287-297. https:// doi.org/10.1593/neo.07971

69. Kusaba T. Expression of p-STAT3 in human colorectal adenocarcinoma and adenoma; correlation with clinicopathological factors. Journal of Clinical Pathology. 2005 Aug 1;58(8):833-838. https://doi. org/10.1136/jcp.2004.023416

70. Chen LF, Cohen EEW, Grandis JR. New Strategies in Head and Neck Cancer: Understanding Resistance to Epidermal Growth Factor Receptor Inhibitors. Clin- ical Cancer Research. 2010 Apr 20;16(9):2489-2495. https://doi.org/10.1158/1078-0432.ccr-09-2318

71. Yang J, Zhong $X$, Yum H, Lee H, Kundu JK, Na H, Surh Y. Curcumin Inhibits STAT3 Signaling in the Colon of Dextran Sulfate Sodium-treated Mice. Journal of Cancer Prevention. 2013 Jun 30;18(2):186-191. https://doi.org/10.15430/jcp.2013.18.2.186

72. Chung SS, Dutta P, Chard N, Wu Y, Chen Q, Chen G, Vadgama J. A novel curcumin analog inhibits canonical and non-canonical functions of telomerase through STAT3 and NF-KB inactivation in colorectal cancer cells. Oncotarget. 2019 Jul 16;10(44):45164531. https://doi.org/10.18632/oncotarget. 27000

73. Yang L, Lin S, Xu L, Lin J, Zhao C, Huang X. Novel activators and small-molecule inhibitors of STAT3 in cancer. Cytokine \& Growth Factor Reviews. 2019 Oct;49:10-22. https://doi.org/10.1016/j. cytogfr.2019.10.005

74. Li C, Chen C, An Q, Yang T, Sang Z, Yang Y, Ju Y, Tong A, Luo Y. A novel series of napabucasin derivatives as orally active inhibitors of signal transducer and activator of transcription 3 (STAT3). European Journal of Medicinal Chemistry. 2019 Jan;162:543-554. https:// doi.org/10.1016/j.ejmech.2018.10.067

75. Proia DA, Foley KP, Korbut T, Sang J, Smith D, Bates RC, Liu Y, Rosenberg AF, Zhou D, Koya K, Barsoum J, Blackman RK. Multifaceted Intervention by the Hsp90 Inhibitor Ganetespib (STA-9090) in Cancer Cells with Activated JAK/STAT Signaling. Gires O. PLoS ONE. 2011 Apr 14;6(4):e18552. https://doi.org/10.1371/ journal.pone.0018552

76. Nagaraju GP, Park W, Wen J, Mahaseth H, Landry J, Farris AB, Willingham F, Sullivan PS, Proia DA, El-Hariry I, Taliaferro-Smith L, Diaz R, El-Rayes BF. Erratum to: Antiangiogenic effects of ganetespib in colorectal cancer mediated through inhibition of HIF-1a and STAT-3. Angiogenesis. 2013 Aug 2;16(4):919-919. https://doi.org/10.1007/s10456-013-9373-6 